\title{
Recurrent Malignant Neoplasm
}

National Cancer Institute

\section{Source}

National Cancer Institute. Recurrent Malignant Neoplasm. NCI Thesaurus. Code C4813.

The reemergence of a malignant neoplasm after a period of remission. 